\title{
Influência do silício na produção e na qualidade de frutos do morangueiro
}

\section{Influence of silicon on production and fruit quality of strawberry}

\author{
Maria Ligia de Souza Silva ${ }^{1 *}$; Juliano Tadeu Vilela de Resende²; \\ Anderson Ricardo Trevizam ${ }^{3}$; Alex Sandro Torre Figueiredo ${ }^{4}$; Kélin Schwarz ${ }^{5}$
}

\section{Resumo}

\begin{abstract}
No Brasil, a cultura do morangueiro é uma importante atividade para pequenos e médios agricultores. Entre os fatores importantes para a cultura está a adubação, que pode interferir na produção e qualidade dos frutos. O silício $(\mathrm{Si})$ é um dos elementos pouco estudados na adubação, que demonstrou benefícios para várias culturas. O objetivo do presente trabalho foi avaliar a influência do Si sobre a produção e a concentração de antocianinas e acidez titulável nos frutos e leitura SPAD (clorofila) nas folhas do morango. O experimento foi realizado em casa de vegetação utilizando-se vasos com 14,5 kg de solo corrigido, adubado e três mudas (cultivar Milsei Tudla) foram transplantadas para os vasos. Os tratamentos constituíram da aplicação de Si nas doses de 0;12,5;25, 50 e $100 \mathrm{mg} \mathrm{kg}^{-1}$, via solo ou foliar. Durante o experimento foi realizado a leitura SPAD (clorofila) e ao final do experimento a parte área foi coletada, seca, pesada, moída e analisada em relação ao teor e acúmulo de Si. Os frutos coletados foram pesados e analisados a concentração de antocianinas e acidez titulável. As adubações com Si, aplicadas via solo ou foliar, contribuíram para o aumento da produção de frutos, em especial com a aplicação via solo. A aplicação via foliar ou solo promoveu aumento nos valores de acidez titulável e antocianinas. As doses de Si aplicadas via solo ou foliar influenciaram na leitura SPAD (clorofila), das folhas. O Si independente da forma de aplicação promoveu melhorias no cultivo do morangueiro.

Palavras-chave: Nutrição de plantas, elemento benéfico, Fragaria x ananassa sp
\end{abstract}

\begin{abstract}
In Brazil, the culture of strawberries is an important activity for small and medium farmers. Among the important factors for culture is fertilization, which can interfere in production and fruit quality. Silicon ( $\mathrm{Si}$ ) is one of the little studied in fertilization, which demonstrated some beneficial to several different cultures. The objective of this study was to evaluate the influence of $\mathrm{Si}$ on production and concentration of anthocyanin and titratable acid in the fruit and reading SPAD (chlorophyll) in the leaves of the strawberry. The experiment was conducted in a greenhouse using pots containing $14.5 \mathrm{~kg}$ of limed soil, fertilized and three plants (cultivar Milsei Tudla) were transplanted to pots. Treatments consisted of application of Si at $0,12.5,25,50$ and $100 \mathrm{mg} \mathrm{kg}^{-1}$ rates, via soil or foliar. During this experiment the reading of SPAD (chlorophyll) and the end of the experiment, the shoots was collected, dried,
\end{abstract}

\footnotetext{
${ }^{1}$ Prof $^{\mathrm{a}}$ Dr $^{\mathrm{a}}$ Adjunto, Dept $^{\mathrm{o}}$ de Agronomia, Universidade Estadual do Centro Oeste, UNICENTRO, Campus Cedeteg, Guarapuava, PR.E-mail:mlsousi@hotmail.com

${ }^{2}$ Prof Dr. Adjunto D, Dept ${ }^{\circ}$ de Agronomia, UNICENTRO, Campus Cedeteg, Guarapuava, PR. E-mail: jresende@unicentro.br

${ }^{3}$ Químico, Pós-Doutorando do Dept ${ }^{\circ}$ de Agronomia, UNICENTRO, Campus Cedeteg, Guarapuava, PR. E-mail: aanrt@hotmail. com

${ }^{4}$ Eng $^{\circ}$ Agr $^{\circ}$, Discente de Mestrado em Agronomia do Dept ${ }^{\circ}$ de Agronomia, UNICENTRO, Campus Cedeteg, Guarapuava, PR. E-mail: alexfiqueiredo@hotmail.com

${ }^{5}$ Nutricionista, Discente de Doutorado em Ciências no Laboratório de Irradiação de Alimentos e Radioentomologia, Centro de Energia Nuclear na Agricultura, CENA/USP, Piracicaba, SP. E-mail: kelinschwarz@hotmail.com

* Autor para correspondência
} 
weighed, ground and analyzed by content and accumulation Si. The fruits were weighed and analyzed the concentration of anthocyanin, titratable acidity and $\mathrm{Si}$ concentration. The fertilization with $\mathrm{Si}$, via soil or foliar applied, contributed to the increase in fruit production, especially with the application via soil. Applying foliar or soil promoted an increase in the values of titratable acidity and anthocyanins. Rates of Si via soil or foliar applied influenced the reading SPAD (chlorophyll), in the leaves. The Si independent of the form of application promoted improvements in strawberry crop.

Key words: Plant nutrition, beneficial element, Fragaria $x$ ananassa $\mathrm{sp}$

\section{Introdução}

A produção brasileira de morango (Fragaria $\mathrm{x}$ ananassa Duch.) tem aumentado nos últimos anos, chegando a apresentar produção de 37,5 mil toneladas, obtida numa área estimada em 3.500 ha (COSTA et al., 2011). No manejo da cultura do morango a adubação é uma das principais práticas responsáveis pelo aumento da produtividade, qualidade e conservação pós-colheita (VIGNOLO et al., 2011). Mesmo sendo uma prática importante, de acordo com Prezotti (2006) poucos trabalhos abordam sobre a nutrição da cultura no Brasil.

Um dos elementos minerais que tem despertado interesse por parte dos pesquisadores é o silício (Si) devido aos benefícios que este elemento traz a algumas culturas agrícolas. O Si é o segundo elemento em abundância na crosta terrestre participando da constituição dos principais minerais do solo (REIS et al. 2007). No solo, a forma solúvel pode ser proveniente da decomposição de resíduos vegetais, da aplicação de fertilizantes silicatados ou da transformação de compostos minerais no solo, sendo absorvido pelas plantas na forma de ácido monossilícico, podendo ser perdido pela polimerização do ácido silícico, lixiviação, adsorção em óxidos e hidróxidos de Fe e Al (KORNDÖRFER, 2006; KORNDÖRFER; VIDAL; KORNDÖRFER, 2010).

Para a grande maioria das plantas cultivadas, inclusive o morangueiro, o Si pode ser considerado como um elemento benéfico, porém estudos com hortaliças são poucos conhecidos e os benefícios decorrentes do Si estão as funções estruturais e de defesa das plantas (KORNDÖRFER, 2006). Dentre as vantagens destacam-se as modificações que este elemento propicia na fisiologia da planta, na forma de compostos que são depositados nos tecidos formando uma estrutura silificada, que reduz o consumo de água pela planta e o ataque de pragas e doenças, devido à dificuldade de penetração no interior dos tecidos (REIS et al., 2007). Outro fator importante do Si para as culturas é a melhoria da arquitetura das plantas, que se desenvolvem com folhas mais eretas facilitando a interceptação dos raios solares. $\mathrm{O}$ aumento na taxa fotossintética das plantas contribui para aumentar a quantidade total de fotoassimilados produzidos durante a fotossíntese, culminando com o maior desenvolvimento $\mathrm{e}$ crescimento das partes vegetais (TAIZ; ZEIGER, 2004).

A aplicação de Si pode resultar em aspectos negativos, ao agricultor, quando não se obtém aumento de produtividade, porém quando o elemento proporciona melhor resistência quanto aos fatores bióticos e abióticos adversos, como o ataque de pragas e doenças ou ao estresse hídrico (KORNDÖRFER, 2006), resulta em economia nos custos de produção. Neste sentido as contribuições significativas do Si no desenvolvimento das plantas podem gerar resultados favoráveis na qualidade pós colheita dos frutos, apresentando alterações na concentração de antocianinas, sólidos solúveis e acidez titulável de modo a apresentar maior ou menor qualidade comercial.

Pereira, Vitti e Korndörfer (2003) verificaram que as escórias, o xisto e o termofosfato utilizados como fonte de Si foram capazes de liberar o Si no solo e aumentar a absorção pelo tomateiro, porém as fontes não alteraram a produtividade da cultura. Para o pepino submetido à aplicação de Si foi observada redução no ataque do míldio pulverulento 
e o mesmo ocorreu para a melancia (BÉLANGER et al., 1995). A diminuição da mortalidade de plantas de pepino causada por Pythium ultimum foi observada por Cherif et al. (1992) com aplicação de Si. Segundo Pulz et al. (2008), o fornecimento de Si para a cultura da batata resultou em maior altura para às plantas, menor acamamento das hastes e maior produção de tubérculos comercializáveis.

Diante dos benefícios que o Si pode promover nas plantas, o objetivo do presente trabalho foi avaliar a influência do Si sobre a produção e a concentração de antocianinas e acidez titulável nos frutos e leitura SPAD (clorofila) nas folhas do morango.

\section{Material e Métodos}

O experimento foi realizado em casa de vegetação no período de julho a dezembro de 2009. $\mathrm{O}$ experimento foi conduzido em vasos plásticos com capacidade de $15 \mathrm{~kg}$ que foram preenchidos com $14,5 \mathrm{~kg}$ de solo peneirado em peneira de malha de $4 \mathrm{~mm}$. As características químicas do solo se encontram na Tabela 1.

Tabela 1. Características químicas e físicas do solo utilizado no experimento.

\begin{tabular}{|c|c|c|}
\hline Características & Unidade & resultado \\
\hline $\mathrm{pH}\left(\mathrm{H}_{2} \mathrm{O} / 1: 2,5\right)$ & & 5,5 \\
\hline Matéria orgânica & $\mathrm{g} \mathrm{dm}^{-3}$ & 28 \\
\hline Fósforo (Mehlich-1) & $\mathrm{mg} \mathrm{dm}{ }^{-3}$ & 0,9 \\
\hline Potássio (Mehlich-1) & $\mathrm{mmol}_{\mathrm{c}} \mathrm{dm}^{-3}$ & 0,5 \\
\hline Cálcio $\left(\mathrm{KCl} 1 \mathrm{~mol} \mathrm{~L}^{-1}\right)$ & $\mathrm{mmol}_{\mathrm{c}} \mathrm{dm}^{-3}$ & 8 \\
\hline Magnésio $(\mathrm{KCl} \mathrm{1mol} \mathrm{L-1})$ & $\mathrm{mmol}_{\mathrm{c}} \mathrm{dm}^{-3}$ & 5 \\
\hline Enxofre $\left(\mathrm{Ca}\left(\mathrm{H}_{2} \mathrm{PO}_{4}\right)_{2}\right)$ & $\mathrm{mg} \mathrm{dm}{ }^{-3}$ & 23 \\
\hline $\mathrm{H}+\mathrm{Al}(\mathrm{SMP})$ & $\mathrm{mmol}_{\mathrm{c}} \mathrm{dm}^{-3}$ & 50 \\
\hline Soma de Bases (SB) & $\mathrm{mmol}_{\mathrm{c}} \mathrm{dm}^{-3}$ & 13,5 \\
\hline Capacidade Troca Cationica (T) & $\mathrm{mmol}_{\mathrm{c}} \mathrm{dm}^{-3}$ & 63,5 \\
\hline Saturação de Bases (V) & $\%$ & 21,2 \\
\hline Silício & $m g \mathrm{dm}^{-3}$ & 12 \\
\hline B (água quente) & $\mathrm{mg} \mathrm{dm}^{-3}$ & 0,20 \\
\hline $\mathrm{Cu}$ (DTPA) & $\mathrm{mg} \mathrm{dm}{ }^{-3}$ & 1,1 \\
\hline $\mathrm{Fe}$ (DTPA) & $\mathrm{mg} \mathrm{dm}^{-3}$ & 135 \\
\hline Mn (DTPA) & $\mathrm{mg} \mathrm{dm} \mathrm{m}^{-3}$ & 35,1 \\
\hline Zn (DTPA) & $\mathrm{mg} \mathrm{dm} \mathrm{m}^{-3}$ & 1,6 \\
\hline Areia & $\mathrm{g} \mathrm{kg}^{-1}$ & 260 \\
\hline Silte & $\mathrm{g} \mathrm{kg}^{-1}$ & 130 \\
\hline Argila & $\mathrm{g} \mathrm{kg}^{-1}$ & 610 \\
\hline Textura & & \\
\hline
\end{tabular}

Fonte: Elaboração dos autores.

Foi realizada a calagem do solo para elevar a saturação por bases a $80 \%$, com aplicação 18,6 $\mathrm{g}$ de $\mathrm{CaO}$ e 6,8 g $\mathrm{MgO}$ por vaso. Os solos, nos respectivos vasos, foram incubados por 7 dias com umidade a $60 \%$ da capacidade retenção de água. A adubação de plantio foi realizada uma semana após as correções de solo, com base na análise de solo utilizando-se $6 \mathrm{~g}$ do fertilizante $\mathrm{N}-\mathrm{P}_{2} \mathrm{O}_{5}-\mathrm{K}_{2} \mathrm{O}$ de fórmula 04-14-08, por vaso. Para a correção e adubação foram seguidas as recomendações para a cultura de acordo com Raij et al. (1997).

Cada vaso recebeu três mudas de morango, cultivar Milsei Tudla, que foram extraídas do matrizeiro do setor de olericultura da universidade, 
selecionadas de acordo com o diâmetro de coroa (10 a $12 \mathrm{~mm}$ de diâmetro) e tamanho de raiz (aproximadamente $12 \mathrm{~cm}$ ). A irrigação foi realizada diariamente e de acordo com a necessidade das plantas.

O delineamento experimental utilizado foi inteiramente casualizado, com quatro repeticções. Os tratamentos constaram de quatro doses de Si e um tratamento controle (sem adição de $\mathrm{Si}$ ) e duas formas de aplicação, via solo e foliar, do mesmo produto. As doses de $\mathrm{Si}$, para os dois modos de aplicação, foram de $0 ; 12,5 ; 25,50$ e $100 \mathrm{mg} \mathrm{kg}^{-1}$ de solo. A fonte de Si (Agri Silß) utilizada no experimento apresentava uma concentração de $98 \%$ de $\mathrm{SiO}_{2}$ e 6,5\% de $\mathrm{Si}$ solúvel.

As doses de Si dos tratamentos via solo foram realizadas em uma única aplicação 15 dias após o transplante das mudas mediante a incorporação superficial. Os tratamentos fornecidos via foliar foram aplicados através de um pulverizador manual. Cada tratamento foi diluído em $200 \mathrm{~mL}$ de água e aplicados nas respectivas doses de $\mathrm{Si}$, as quais foram divididas em 12 aplicações, e o somatório das aplicações foliares corresponderam às mesmas doses aplicadas via solo. Nos vasos com tratamento foliar foi colocado um filme de plástico imitando o mulching que é utilizado a campo nos canteiros, com o objetivo de impedir que a solução contendo Si entrasse em contanto com o solo, evitando-se sua absorção. Para as aplicações via foliar foi construída uma armação de plástico visando proteger os vasos ao redor para não comprometer os demais tratamentos. Após a aplicação, o excesso de solução que permanecia sobre o mulching era retirado com o auxilio de uma seringa evitando a entrada da solução no interior do vaso.

Durante a condução do experimento foram realizados tratos fitossanitários para o controle de ácaro e doenças através da pulverização de acaricidas e fungicidas quando necessário. Foi realizada adubação de manutenção em todos os vasos, com aplicações foliares de micronutrientes mensalmente, após o transplante da mudas, na dose de $10 \mathrm{~mL} \mathrm{~L}^{-1}$ de Wuxal® Florada e de cloreto de potássio em duas aplicações de $2 \mathrm{~g}$ por vaso.

Aos 120 dias após os transplante das mudas foi realizada a leitura da concentração da clorofila $a$ e $b$ nos tratamentos, correspondendo ao início da produção dos frutos, realizada nas folhas novas, $3^{\mathrm{a}}$ e $4^{\mathrm{a}}$ folha recém desenvolvida, de cada vaso. As leituras foram realizadas nas três plantas conduzidas no vaso, sendo utilizada a média dos valores. As determinações dos níveis das clorofilas $a$ e $b$ foram realizadas pelo uso do medidor portátil de clorofila SPAD-502 [Soil-Plant Analysis Development (SPAD) Section. Minolta Camer Co., Ltd, Japão] que mede de modo não destrutivo e instantâneo a transmitância de luz através da folha, no comprimento de onda com pico em $650 \mathrm{~nm}$, região de alta absorbância pelas moléculas de clorofila, e com pico em 940 nm, na qual a absorbância pela folha é baixa, servindo como um fator de correção para o teor de água ou espessura da folha (MINOLTA, 1989). A clorofila total foi calculada pela soma das clorofilas $a$ e $b$.

Os frutos dos morangueiros foram colhidos semanalmente ao longo do experimento, pesados e a produção total foi calculada com o somatório de todas as colheitas realizadas ao longo do ciclo produtivo. Ao final da colheita dos frutos, a parte aérea das plantas foram cortadas rente ao solo, lavadas, secas em estufa a $65{ }^{\circ} \mathrm{C}$, pesadas e moídas e analisadas em relação ao teor de Si de acordo com (KORNDÖRFER, PEREIRA, NOLLA, 2004). Nos frutos foram analisados: a) o teor de sólidos solúveis (SS) o qual foi obtido pela leitura direta em refratômetro de bancada (marca Optech modelo RMT), utilizando polpa homogeneizada e filtrada, a temperatura ambiente, obtendo-se os valores em graus Brix (Brix); b) a acidez titulável (AT) determinada pelo método titulométrico, conforme descrito pelo Instituto Adolfo Lutz (IAL, 2005); c) o teor de antocianinas totais determinado pelo método diferencial de $\mathrm{pH}$ descrito por Giusti e Wrosltad (2001) e d) relação SS/AT obtida pela razão entre os $\mathrm{SS}$ e a porcentagem de AT. 
Os resultados das doses de Si foram submetidos à análise de variância pelo teste $\mathrm{F}$, ao nível de significância de 1 e 5\% de probabilidade. Quando houve interação entre o modo de aplicação e as doses de $\mathrm{Si}$, realizou-se desdobramento e para as doses adotou-se a equação de regressão que melhor se ajustou aos dados, a qual foi escolhida com base na significância dos coeficientes de regressão a $5 \%$ de probabilidade pelo teste $\mathrm{F}$, com o uso do programa estatístico SAS.

Os dados foram submetidos à análise de variância pelo teste F. Os dados provenientes do fator doses de Si e da interação da forma de aplicação do Si (solo ou foliar) foram analisadas por meio de regressão polinomial.

\section{Resultados e Discussão}

As doses de $\mathrm{Si}$ utilizadas influenciaram significativamente na produção dos frutos do morangueiro, assim como o modo de aplicação do Si (Tabela 2). Porém, a interação entre a dose e o modo de aplicação não afetaram na produção de frutos. Observa-se na Figura 1 que houve acréscimo na produção de frutos por vaso com o aumento das doses de $\mathrm{Si}$, tanto via solo quanto via foliar, em comparação ao tratamento controle. Os resultados comprovam que, quando o $\mathrm{Si}$ foi disponibilizado via solo, as plantas apresentaram, em todos os tratamentos, produção superior em comparação àquelas que receberam o Si via foliar. A máxima produção de frutos (934,3 g vaso $\left.{ }^{-1}\right)$ com o fornecimento do Si via solo foi obtida com a dose de $65,5 \mathrm{mg} \mathrm{kg}^{-1}$. Por outro lado a máxima produção $\left(815,1 \mathrm{~g} \mathrm{vaso}^{-1}\right)$ dos tratamentos oriundos da aplicação via foliar foi obtida com a dose de 86,2 $\mathrm{mg} \mathrm{kg}^{-1}$. As plantas que receberam o Si via foliar necessitariam de doses superiores para se equiparar aos resultados obtidos com aplicação via solo.

Um ponto importante pelo qual o Si deve ter contribuído para a maior produção dos tratamentos via solo estaria relacionado à influência que este elemento apresenta sobre outros elementos de grande importância na nutrição das plantas e que se encontram adsorvidos no solo, como é caso do fósforo. Reis et al. (2007) demonstraram que o Si tem importante papel sobre o metabolismo do fósforo na planta, uma vez que ambos são absorvidos pelos mesmos sítios na raiz, devido à similaridade molecular existente entre as duas formas aniônicas $\left(\mathrm{H}_{2} \mathrm{PO}_{4}^{-}\right.$e $\left.\mathrm{H}_{3} \mathrm{SiO}_{4}^{-}\right)$. Os autores também relataram que, da mesma forma em que existe a competição pela absorção nas raízes, esses dois ânions também competem pelos sítios de adsorção do solo. Assim, após aplicação de $\mathrm{Si}$ no solo os anions $\mathrm{SiO}_{4}^{-}$liberados pela sua dissociação são capazes de dessorver os anions $\mathrm{PO}_{4}^{-}$que estão ligados aos coloides, fazendo com que estes fiquem disponíveis na solução do solo para a absorção através das raízes. A ocorrência dessa reação durante todo o ciclo da cultura proporciona o fornecimento de uma quantidade significativa de fósforo para as plantas, propiciando aumento de produção. Nos tratamentos onde o Si foi fornecido via foliar, não ocorreu a interação com outros elementos presentes no solo.

Tabela 2. Valores de F e nível de significância obtido na análise de variância para teor e acúmulo de Si, antocianinas, acidez titulável, SS/AT e o modo de aplicação do Si.

\begin{tabular}{lcccccc}
\hline $\begin{array}{c}\text { Fonte de } \\
\text { Variação }\end{array}$ & $\begin{array}{c}\text { Produção } \\
\text { de Frutos }\end{array}$ & Teor de Si & $\begin{array}{c}\text { Acúmulo } \\
\text { de Si }\end{array}$ & Antocianinas & $\begin{array}{c}\text { Acidez } \\
\text { titulável }\end{array}$ & SS /AT \\
\hline Dose de Si (D) & $6,600^{*}$ & $170,6^{*}$ & $52,8^{*}$ & $33,9^{*}$ & $7,47^{* *}$ & $3,85^{* *}$ \\
Aplicação (A) & $8,746^{*}$ & $147,5^{*}$ & $16,6^{*}$ & $6,27^{* *}$ & $0,12 \mathrm{~ns}$ & $0,18 \mathrm{~ns}$ \\
Interação D x A & $0,713 \mathrm{~ns}$ & $30,5^{*}$ & $10,8^{*}$ & $9,85^{*}$ & $2,40 \mathrm{~ns}$ & $2,43 \mathrm{~ns}$ \\
CV $(\%)$ & 10,2 & 11,5 & 22,3 & 10,4 & 6,3 & 6,3 \\
\hline
\end{tabular}

**, * e ns são respectivamente, significativo a 5\%,1\% e não significativo pelo teste $\mathrm{F}$.

Fonte: Elaboração dos autores. 
Figura 1. Produção de frutos de morangueiros cv. Milsei Tudla em função das doses de Si aplicados via solo ou foliar. *Indica significância do modelo a 5\% probabilidade respectivamente pelo teste $\mathrm{F}$.

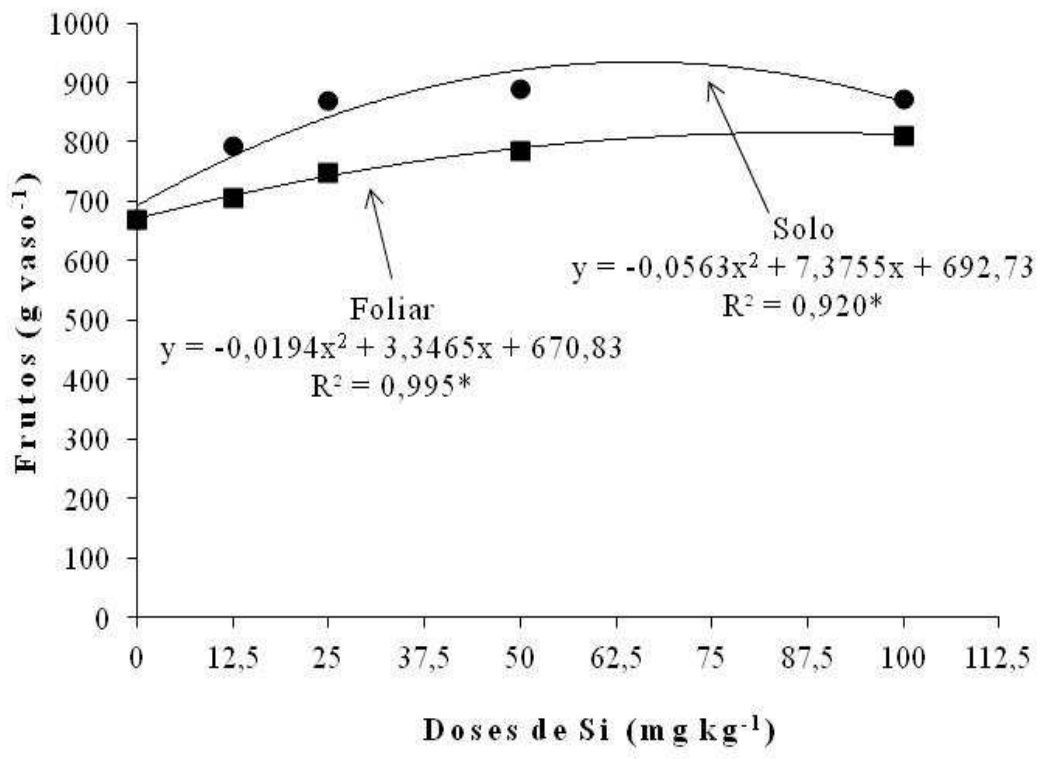

Fonte: Elaboração dos autores.

$\mathrm{Na}$ literatura são verificados resultados positivos de produção para a cultura da cana-de-açúcar (SAVANT et al., 1999) e para o arroz (SANTOS et al., 2003) quando se aplica Si. Entretanto Pereira, Vitti e Korndörfer (2003) verificaram que as fontes de Si estudadas pelos autores para a cultura do tomateiro não promoveram aumentos significativos de produção. A produção das culturas em relação à aplicação do Si pode estar relacionada ao aumento de resistência das plantas ao ataque de doenças, principalmente a fungos e insetos (KORNDÖRFER; VIDAL; KORNDÖRFER, 2010). Além disso, o acúmulo de Si nos órgãos de transpiração promove a formação de uma dupla camada de sílica, o que causa redução da transpiração por diminuir a abertura dos estômatos limitando a perda de água (KORNDÖRFER; VIDAL; KORNDÖRFER, 2010), consequentemente levando a uma maior produção.

Procurando verificar a qualidade dos frutos oriundos da aplicação com Si no experimento foram analisados os sólidos solúveis (SS), antocianinas e acidez titulável em função das doses de Si aplicadas.
Estas variáveis foram influenciadas pelas doses de $\mathrm{Si}$, porém somente a antocianina apresentou efeito significativo pelo modo de aplicação (Tabela 2). Em relação à interação entre as doses de $\mathrm{Si}$ e o modo de aplicação somente à antocianina apresentou significância.

A característica SS apresentou aumento, porém não significativo, de uma unidade em relação ao tratamento controle, ou seja, passou de 6 para $7^{\circ}$ Brix, independentemente da dose ou forma de aplicação do Si (Tabela 3). Segundo Namesny (1999) e Mitchell et al. (1996), os valores recomendados para os frutos do morangueiro para um sabor aceitável corresponde a $7^{\circ}$ Brix. Outro fator preponderante, neste caso utilizando mais na comercialização do tomate, esta que quanto maior o teor de SS, maior será o rendimento industrial e menor o gasto de energia no processo de concentração da polpa, onde a elevação de um ${ }^{\circ}$ Brix na matéria-prima há um incremento de $20 \%$ no rendimento industrial (SILVA; GIORDANO, 2000). 
Tabela 3. Sólidos solúveis e relação SS/AT nos frutos do morango em função das doses de Si e modo de aplicação.

\begin{tabular}{ccccc}
\hline \multirow{2}{*}{$\begin{array}{c}\text { Dose de Si } \\
\mathrm{mg} \mathrm{kg}^{-1}\end{array}$} & \multicolumn{2}{c}{ Sólidos Solúveis } & \multicolumn{2}{c}{ Relação SS / AT } \\
\cline { 2 - 5 } & Foliar & Solo & Foliar & Solo \\
\hline 0 & 6 & 6 & 6,3 & 6,3 \\
2,5 & 7 & 7 & 6,7 & 7,1 \\
50 & 7 & 7 & 6,7 & 7,0 \\
100 & 7 & 7 & 5,9 & 6,3 \\
& 7 & 7 & 6,5 & 6,2 \\
\hline
\end{tabular}

Fonte: Elaboração dos autores.

A aplicação de $\mathrm{Si}$, conforme se observa na figura 2A, proporcionou aumento da concentração de antocianinas em relação aos valores obtidos no tratamento controle. Os maiores valores de antocianinas foram encontrados com a aplicação de Si foliar, e o maior valor de antocianina obtido através da equação descrita na figura 2A, 8,04 mg de cianidina-3-glicosideo $100 \mathrm{~g}^{-1}$, foi obtido com aplicação de $71,5 \mathrm{mg} \mathrm{kg}^{-1}$ de $\mathrm{Si}$, representando um acréscimo de 89,2\% em relação ao tratamento controle. $\mathrm{Na}$ aplicação via solo o maior valor de antocianina, $6,8 \mathrm{mg}$ de cianidina-3-glicosideo 100 $\mathrm{g}^{-1}$, foi obtido com aplicação de $69,5 \mathrm{mg} \mathrm{kg}^{-1}$ de $\mathrm{Si}$, representando acréscimo de $60 \%$ em relação ao tratamento controle.

As antocianinas são pigmentos importantes para a saúde humana, pois apresentam considerável capacidade de sequestrar radicais livres, evitando danos celulares e prevenindo doenças degenerativas (MEYERS et al., 2003; HEO; LEE, 2005) e comercialmente a coloração dos frutos, pode ser influenciada pelas antocianinas o que contribui muito para a avaliação da qualidade, pois os consumidores fazem correlações entre a cor e a qualidade total de produtos específicos (KAYS, 1999). Valores de antocianinas em morangos são encontrados na literatura, tais como os reportados por Zhang, Vareed e Nair (2005) da cv. All Star que observaram conteúdo de antocianinas totais de 20 mg $100 \mathrm{~g}^{-1}$ de fruta e por Cordenunsi et. al. (2005)

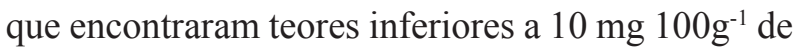
antocianinas em morangos das cv. Campieiro e Oso grande. Os diferentes valores podem ser decorrentes do estágio de maturação dos frutos e da variedade, e segundo Bordignon Junior et al. (2009) as formas de antocianinas podem sofrer interferências de diversos fatores, entre eles a temperatura, o $\mathrm{pH}$ e possíveis ligações com outras substâncias químicas.

A relação SS/AT, que representa a proporção entre os teores de ácidos e açúcares existentes nos frutos, condicionando a sua qualidade organoléptica, isto é, o balanço entre sabor e aroma, não apresentaram diferenças significativas entre as doses de $\mathrm{Si}$, para ambos os modos de aplicação (Tabela 3). O valor médio obtido com aplicação via solo foi de 6,3 e para aplicação via foliar foi de 6,5 .

Outra característica analisada foi a acidez titulável (AT) e os valores para morangos maduros são da ordem de 0,5 a 1,87 g de ácido cítrico $100 \mathrm{~g}^{-1}$ polpa (KADER, 1991). Os valores de AT no presente trabalho estão dentro da faixa citada. Conforme se observa na figura $2 \mathrm{~B}$ a AT obteve maiores valores com a aplicação do Si via foliar, sendo que o maior valor, $1,19 \mathrm{mg}$ de ácido cítrico $100 \mathrm{~g}^{-1}$, foi obtido com a aplicação de $69 \mathrm{mg} \mathrm{kg}^{-1}$ de $\mathrm{Si}$, enquanto que na aplicação via solo o maior valor, $1,13 \mathrm{mg}$ de ácido cítrico $100 \mathrm{~g}^{-1}$, foi obtido com a aplicação $97,5 \mathrm{mg} \mathrm{kg}^{-1}$ de Si. A aplicação de $\mathrm{Si}$, seja via solo ou foliar, promoveu aumento de 3 a $24 \%$ na AT em relação ao tratamento controle. 
Figura 2. Antocianinas (A) e Acidez titulável (B) nos frutos de morangueiros cv. Milsei Tudla em função das doses de Si aplicados via solo ou foliar. *Indica significância do modelo a 5\% probabilidade respectivamente pelo teste $\mathrm{F}$.
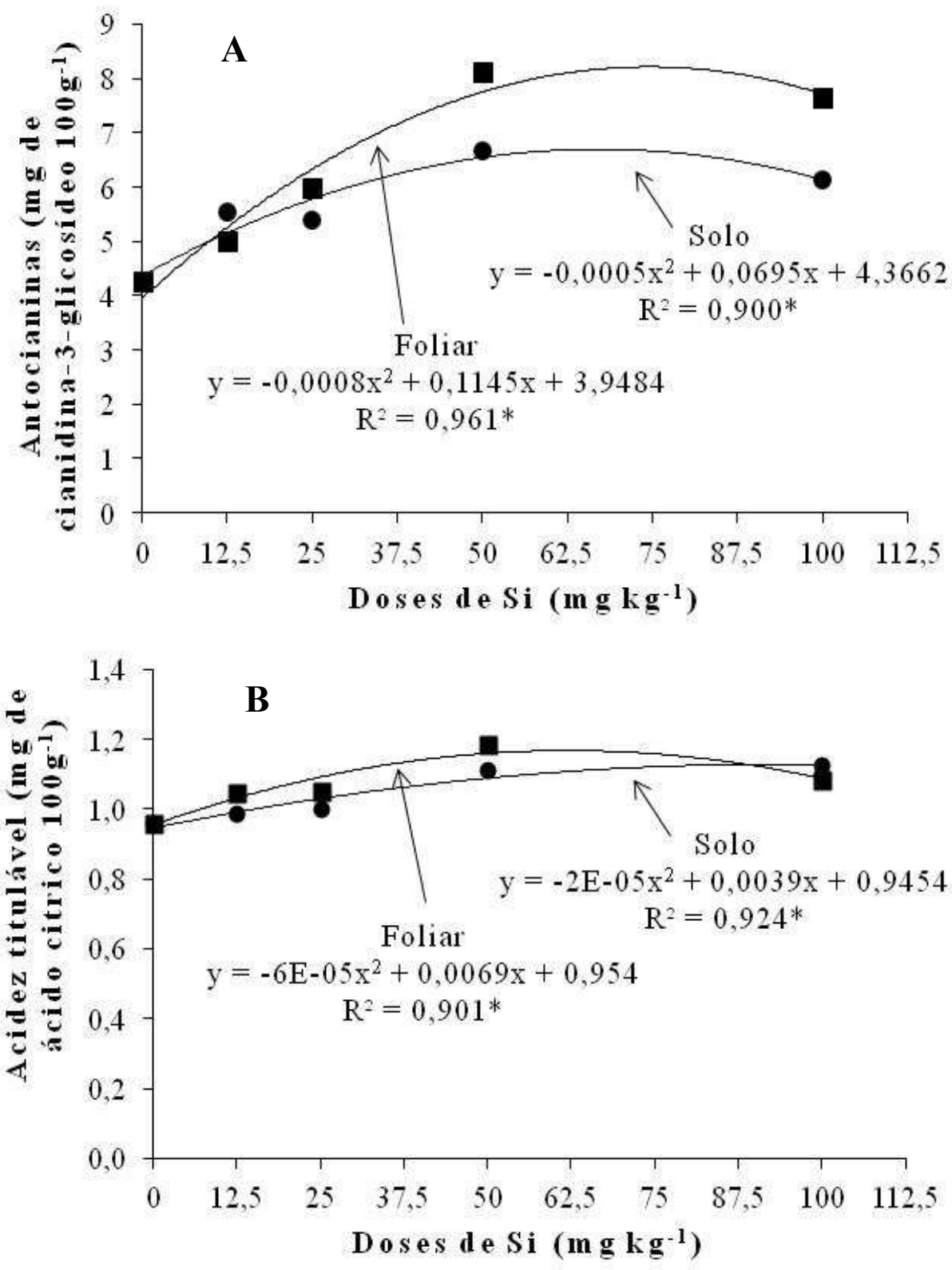

Fonte: Elaboração dos autores.

Considerando-se as variáveis estudadas anteriormente a aplicação de 65,5 a 69,5 mg kg-1 de Si via solo proporcionou ganhos de produção de frutos e nos valores de antocianinas. Quando realizada via foliar nas doses de 69 a $86 \mathrm{mg} \mathrm{kg}^{-1}$ obteve-se ganhos de produtividade de frutos e nos valores de acidez titulável e antocianinas.
Outras propriedades têm sido evidenciadas sobre a melhoria da qualidade de frutos de morango quando foram submetidos à aplicação de Si. Figueiredo et al. (2010), com aplicações foliares de $\mathrm{Si}$, observaram alterações dos teores de ácido cítrico e pH da polpa. Porém, os autores encontraram elevação dos teores totais de açúcares e glicose. Em estudo conduzido por Wang e Galletta 
(1998) foi observado que, com o aumento das doses de Si fornecidas através da adubação, as plantas de morangueiro apresentaram aumento no teor de ácido cítrico e málico nos frutos, e uma redução na quantidade total de açúcares, como a frutose, glicose e sacarose. Entretanto o autor concluiu que a adubação com Si em plantas de morangueiro proporcionou melhoria no metabolismo da planta, devido aos seus efeitos benéficos na fisiologia e anatomia da cultura.

As doses de $\mathrm{Si}$ utilizadas influenciaram significativamente nos teores e acúmulo Si na parte aérea do morangueiro, assim como o modo de aplicação do Si (Tabela 2). A interação entre a dose e o modo de aplicação afetaram no teor e acumulo de Si na parte aérea do morangueiro. As concentrações de Si na parte aérea do morango encontram-se na figura 3A. Os teores de $\mathrm{Si}$ variaram de $4,87 \mathrm{~g} \mathrm{~kg}^{-}$ 1, no tratamento controle, a 70,2 $\mathrm{g} \mathrm{kg}^{-1}$ na dose de $100 \mathrm{mg} \mathrm{kg}^{-1}$, aplicado via solo. Os maiores teores de Si foram encontrados nos tratamentos aplicados via solo, sendo que os valores apresentaram diferença de 24 a 130\% quando comparados aos teores aplicados via foliar, considerando a mesma dose de $\mathrm{Si}$. Os teores de $\mathrm{Si}$ nas plantas podem variar de 1 a $100 \mathrm{~g} \mathrm{~kg}^{-1}$ em base seca, concentrando-se nos tecidos-suporte do caule e das folhas (EPSTEIN, 1999; REIS et al., 2007). Os teores obtidos na parte aérea do morango encontram-se dentro desta faixa.

De acordo com Ma, Miyakey e Takahashi (2001) plantas acumuladoras de Si são aquelas que possuem teor foliar acima de $10 \mathrm{~g} \mathrm{~kg}^{-1} \mathrm{e}$ as não acumuladoras apresentam teor inferior a $5 \mathrm{~g} \mathrm{~kg}^{-1}$. Os teores de $\mathrm{Si}$ nos tratamentos com aplicação via solo ou foliar aumentaram de forma quadrática. Para a aplicação via solo o maior teor de $\mathrm{Si}, 71,7 \mathrm{~g} \mathrm{~kg}^{-1}$, foi obtido com a aplicação de $83,7 \mathrm{mg} \mathrm{kg}^{-1}$ de Si e na aplicação via foliar o maior teor, $43 \mathrm{~g} \mathrm{~kg}^{-1}$, foi obtido com a aplicação 61,2 $\mathrm{mg} \mathrm{kg}^{-1}$ de Si. Segundo Reis et al. (2007) as plantas de morango são caracterizadas como não acumuladoras, constituindo de um baixo teor de Si. Os autores reportam teor de $3,6 \mathrm{~g} \mathrm{~kg}^{-1} \mathrm{em}$ base seca para folhas jovens, valor este inferior ao obtido com o tratamento controle. Teores de Si em folhas de morango, cultivadas em solução nutritiva com $50 \mathrm{mg} \mathrm{L}^{-1}$ de $\mathrm{Si}$, apresentaram teor de $6 \mathrm{~g} \mathrm{~kg}^{-1}$ na formação dos botões florais, $7,7 \mathrm{~g} \mathrm{~kg}^{-1} \mathrm{em}$ início de florescimento e de 12,2 $\mathrm{g} \mathrm{kg}^{-1}$ ao final da floração (MIYAKE; TAKAHASHI, 1986).

O acúmulo de Si na parte aérea do morangueiro aumentou de forma quadrática com as doses de $\mathrm{Si}$, para aplicação via solo. Na aplicação via foliar a equação obtida não foi significativa, entretanto para os dados obtidos o maior acúmulo foi de 265 mg vaso-1 com a aplicação de $50 \mathrm{mg} \mathrm{kg}^{-1}$ de Si. Na aplicação via solo os valores de acúmulo foram superiores aos obtidos com a aplicação via foliar, sendo que o maior valor de acúmulo (468 $\mathrm{mg} \mathrm{vaso}^{-1}$ ) foi obtido com a aplicação de $85 \mathrm{mg} \mathrm{kg}^{-1} \mathrm{de} \mathrm{Si}$. Esse maior acúmulo de Si na parte aérea do morangueiro pode estar relacionados ao fósforo, o qual o $\mathrm{Si}$ tem papel no metabolismo deste elemento, sendo ambos adsorvidos nos mesmos sítios (KHALID; SILVA, 1980).

Um dos resultados do $\mathrm{Si}$ é a melhoria da arquitetura das plantas e consequentemente influencia na concentração das clorofilas, que são pigmentos responsáveis pela captura de luz usada na fotossíntese, sendo elas essenciais na conversão da radiação luminosa em energia química, na forma de ATP e NADPH. No presente trabalho a clorofila total (leitura SPAD) apresentou diferenças entre as formas de aplicação conforme se observa na figura 4A, sendo os maiores valores de clorofila total obtidos com aplicação via foliar. Entretanto, para a aplicação via foliar, o maior valor de clorofila total (51,4 unidades SPAD) foi encontrado com a aplicação de $51,4 \mathrm{mg} \mathrm{kg}^{-1}$ de $\mathrm{Si}$, e na aplicação via solo o maior valor (46,3 unidades SPAD) foi obtido com aplicação de 45,0 mg kg-1 de Si. Diferenças também foram observadas em relação aos tratamentos com Si e o tratamento controle. Resultados sobre o aumento da concentração de clorofila em função do Si foram reportados por Murillo-Amador et al. (2007) para a cultura do feijão, Locarno, Fochi e Paiva (2011) para a cultura da roseira e Adatia e Besford (1986) para a cultura do pepino. 
Figura 3. Teor (A) e acúmulo (B) de Si em folhas do morangueiro cv. Milsei Tudla em função das doses de Si aplicados via solo ou foliar. *Indica significância do modelo a 5\% probabilidade respectivamente pelo teste F.
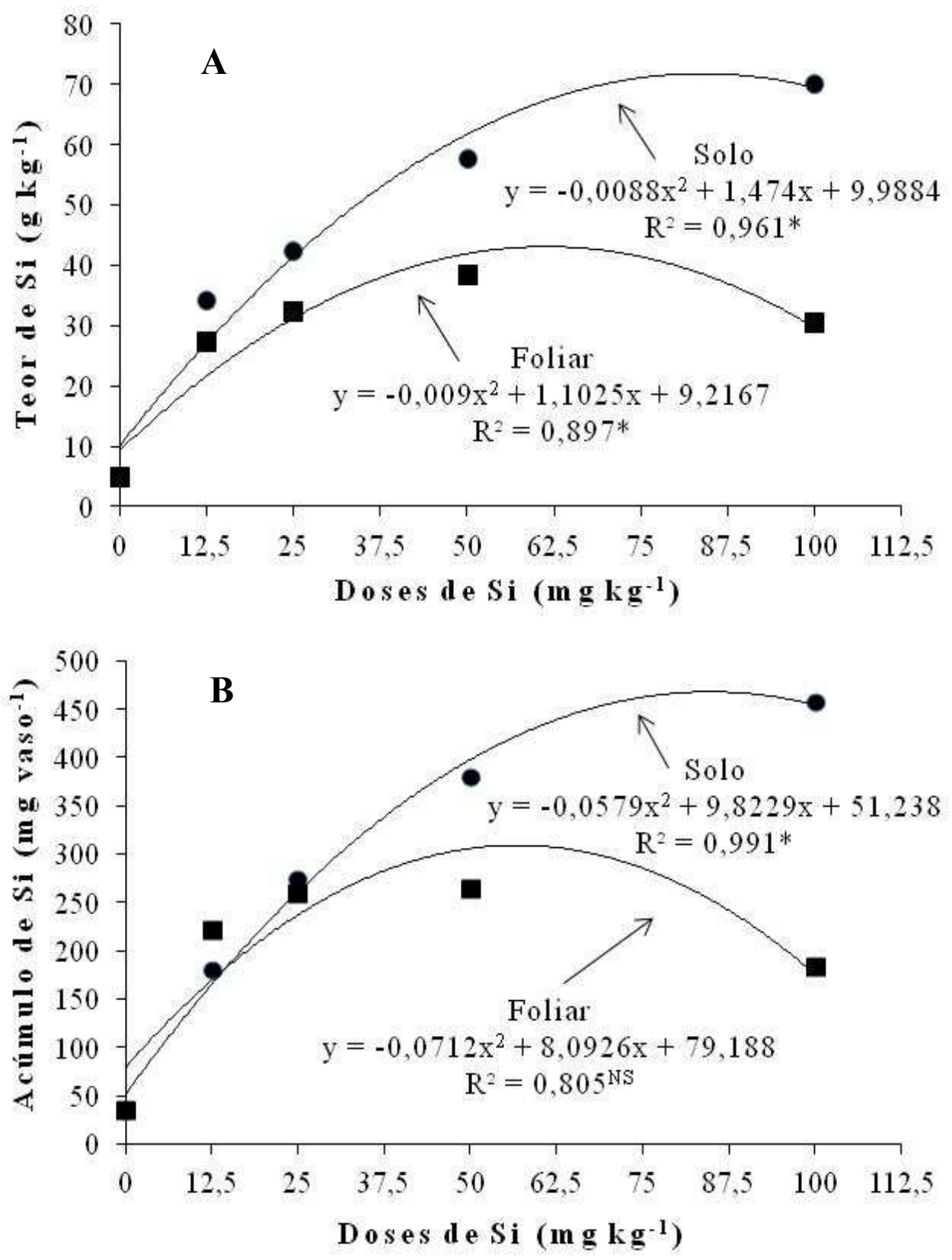

Fonte: Elaboração dos autores. 
Figura 4. Clorofila total (A), clorofila $a$ (B), clorofila $b$ (C) e clorofila $a / b$ (D) em folhas do morangueiro cv. Milsei Tudla em função das doses de Si aplicados via solo ou foliar. *Indica significância do modelo a $5 \%$ probabilidade respectivamente pelo teste $\mathrm{F}$.
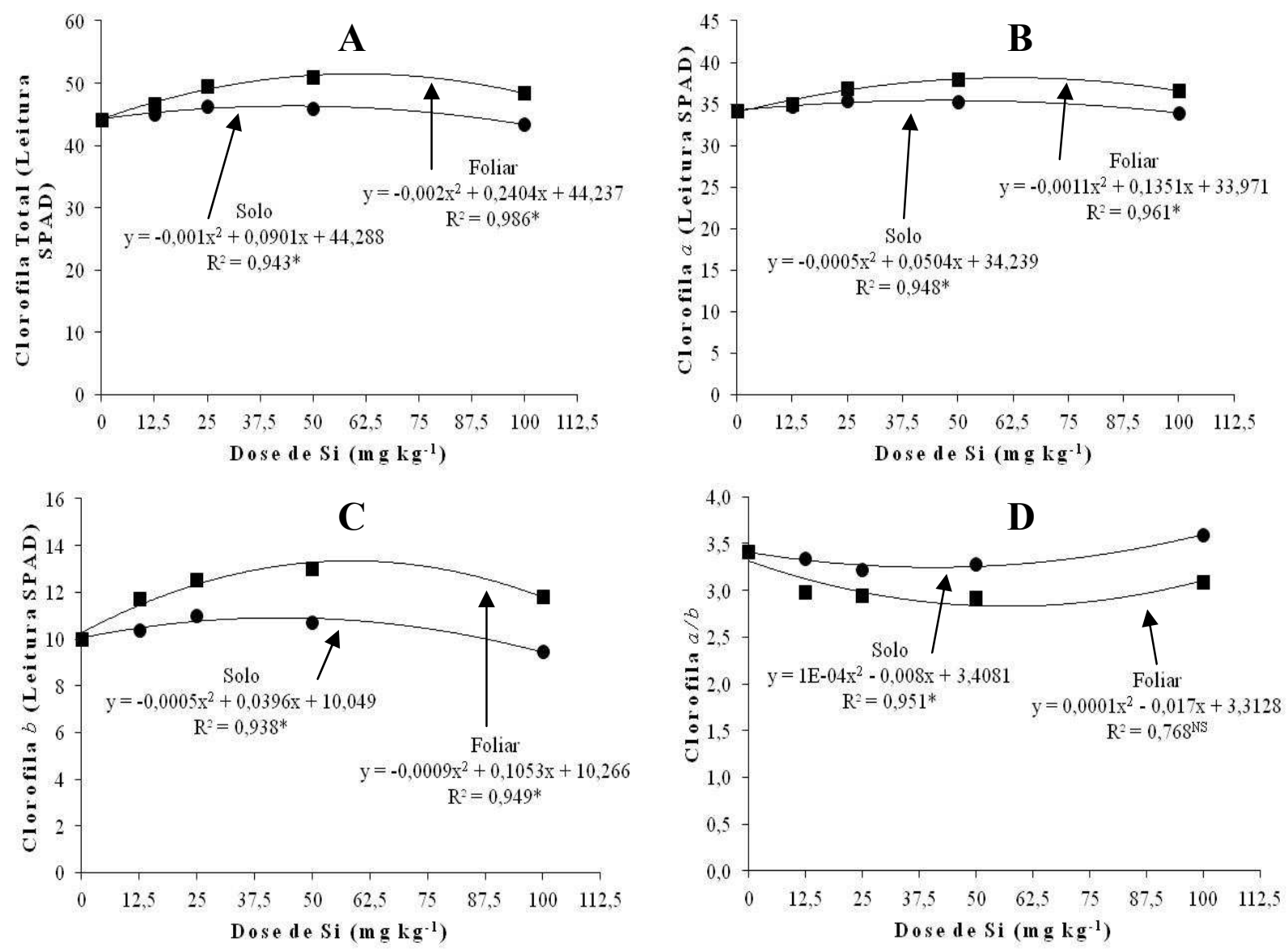

Fonte: Elaboração dos autores.

A explicação para o aumento da clorofila estaria relacionada ao fato do Si absorvido pelas plantas ser depositado abaixo da cutícula epidérmica, formando uma camada dupla de sílica nas células, ocasionando mudança na arquitetura das plantas (RAVEN, 1983). Essa mudança mantêm as folhas mais eretas ocasionando melhoria na interceptação da luz solar, portanto, da fotossíntese (RAVEN, 1983). A maior exposição das folhas promove maior taxa fotossintética e consequentemente maior síntese de clorofila total, modificando a produção de clorofilas $a$ e $b$ (LOCARNO; FOCHI; PAIVA, 2011).
Os valores de clorofila $a$ e $b$ (Figuras 4B e 4C) foram alterados pela forma de aplicação, sendo que os valores foram superiores quando o Si foi aplicado via foliar. Os maiores valores de clorofila $a$ e $b$ aplicados via foliar foram obtidos quando aplicados de 58 a $61 \mathrm{mg} \mathrm{kg}^{-1}$ de Si e quando aplicados via solo de 39 a $51 \mathrm{mg} \mathrm{kg}^{-1}$ de Si. Segundo Kramer e Kozlowski (1979) a clorofila é constantemente sintetizada e destruída (foto-oxidação) em presença de luz, mas sob intensidades luminosas muito altas a velocidade de decomposição é maior, sendo o equilíbrio estabelecido a uma concentração mais baixa. Não só a concentração total de clorofila, mas 
também a proporção entre os diversos tipos desta mudam em função da intensidade luminosa. De uma maneira geral, demonstra-se que a proporção entre clorofila $a$ e $b$ tende a diminuir com a redução da intensidade luminosa (LEE, 1988).

Conforme se observa na figura 4D, para aplicação via solo a proporção de clorofila $a / b$, diminuiu com a aplicação de Si, com exceção a maior dose de Si. Para aplicação via foliar, apesar da equação quadrática não ter sido significativa, os valores observados tendem a uma diminuição da proporção de clorofila $a / b$, quando comparados os tratamentos com Si ao tratamento controle.

A maior proporção relativa de clorofila $b$ em plantas é uma característica importante, pois possibilita a captação de energia de outros comprimentos de onda, e transferência para uma molécula específica de clorofila $a$, que efetivamente toma parte das reações fotoquímicas da fotossíntese (WHATLEY; WHATLEY, 1982). Este aumento relativo pode estar ligado ao aumento da proporção do complexo coletor clorofila $a / b$ proteína, associado ao fotossistema I nos "grana", em relação ao complexo P 700, que contém somente clorofila $a$ - proteína, do fotossistema II nos tilacóides e que é facilmente fotooxidado (THORNBER, 1975).

\section{Conclusões}

As adubações com Si, aplicadas via solo ou foliar, contribuíram para o aumento da produção de frutos do morangueiro por vaso. O tratamento via solo proporcionou maior produção quando comparado ao tratamento via foliar.

A aplicação de Si aplicadas via solo ou foliar influenciaram nos valores de acidez titulável e na concentração de antocianinas nos frutos do morangueiro e na leitura SPAD das folhas do morangueiro.

\section{Referências}

ADATIA, M. H.; BERSFORD, R. T. The effects of silicon on cucumber plants grown in recirculation solution. Annals of Botany, Oxford, v. 58, n. 3, p. 343-351, 1986.

BÉLANGER, R. R.; BOWEN, P. A.; EHRET, D. L.; MENZIES, J. G. Soluble silicon: its role in crop and disease management of greenhouse crops. Plant Disease, Washington, v. 70, n. 4, p. 329-335, 1995.

BORDIGNON JUNIOR, C. L.; FRANCESCATTO, V.; NIENOW, A. A.; CALVETE, E.; REGINATTO, F. H. Influência do $\mathrm{pH}$ da solução extrativa no teor de antocianinas em frutos de morango. Ciência e Tecnologia de Alimentos, Campinas, v. 29, n. 1, p. 183-188, 2009.

CHERIF, F. M.; BENHAMOU, N.; MENZIES, J. G.; BELANGER, R. R. Silicon induced resistance in cucumber plants against Phytium ultimum. Physiologycal and Molecular Plant Pathology, London, v. 41, n. 6, p. 411-425, 1992.

CORDENUNSI, B. R.; GENOVESE, M. I.; NASCIMENTO, J. R. O.; HASSIMOTTO, N. M. A.; SANTOS, R. J.; LAJOLO, M. F. Effects of temperature on the chemical composition and antioxidant activity of three strawberry cultivars. Food Chemistry, Barking, v. 91, n. 1, p. 113-121, 2005.

COSTA, R. C.; CALVETE, E. O.; REGINATTO, F. H.; CECCHETTI, D.; LOSS, J. T.; RAMBO, A; TESSARO, F. Telas de sombreamento na produção de morangueiro em ambiente protegido. Horticultura Brasileira, Brasília, v. 29, n. 1, p. 98-102, 2011.

EPSTEIN, E. Silicon. Annual review of plant physiology and plant molecular biology, Palo Alto, v. 50, n. 1, p. $1-641,1999$.

FIGUEIREDO, F. C.; BOTREL, P. P.; TEIXEIRA, C. P.; PETRAZZINI, L. L.; LOCARNO, M.; CARVALHO, J. G. Pulverização foliar e fertirrigação com silício nos atributos físico-químicos de qualidade e índices de coloração do morango. Ciência e Agrotecnologia, Lavras, v. 34, n. 5, p. 1306-1311, 2010.

GIUSTI, M. M.; WROLSTAD, R. E. Anthocyanins: characterization and measurement with uv-visible spectroscopy. In: WROLSTAD, R. E. Current protocols in food analytical chemistry. New York: John Wiley and Sons, 2001. p. 1-13.

HEO, H. J.; LEE, C. Y. Strawberry and its anthocyanins reduce oxidative stress-induced apoptosis in $\mathrm{PC} 12$ cells. Journal of Agricultural and Food Chemistry, Washington, v. 53, n. 6, p. 1984-1989, 2005. 
INSTITUTO ADOLFO LUTZ - IAL. Métodos fisicoquímicos para análise de alimentos. Brasília: Agência Nacional de Vigilância Sanitária, Ministério da Saúde, 2005. 1018 p.

KADER, A. A. Quality and its maintenance in relation to postharvest physiology of strawberry. In: LUBY, A. The strawberry into the 21st century. Portland, Oregon: Timber Press, 1991. p. 145-152.

KAYS, S. J. Preharvest factors affecting appearance. Postharvest Biology and Technology, Amsterdam, v. 15, n. 1, p. 233-247, 1999.

KHALID, R. A.; SILVA, J. A. Residual effect of calcium silicate em $\mathrm{pH}$ phosphorus and aluminium in a tropical profile. Soil Science and Plant Nutrition, Tokyo, v. 26, n. 1, p. 87-98, 1980.

KORNDÖRFER, G. H. Elementos benéficos. In: FERNANDES, M. S. (Ed.). Nutrição mineral de plantas. Viçosa, MG: Sociedade Brasileira de Ciência do Solo, 2006. p. 355-374.

KORNDÖRFER, G. H.; PEREIRA, H. S.; NOLLA, A. Análise de silício: solo, planta e fertilizante. Uberlândia: Universidade Federal de Uberlândia, 2004. 34 p. (Boletim técnico, 2).

KORNDÖRFER, G. H.; VIDAL, A. A.; KORNDÖRFER, P. H. Elemento benéfico: silício na nutrição de plantas. In: VALE, D. W.; SOUSA, J. I.; PRADO, R. M. (Ed.). Manejo da fertilidade do solo e nutrição de plantas. Jaboticabal: FCAV, 2010. p. 309-327.

KRAMER, T.; KOZLOWSKI, T. Physiology of woody plants. New York: Academic Press, 1979. 811 p.

LEE, D. W. Simulating forest shade to study the development ecology of tropical plants: juvenile growth in three vines in India. Journal of Tropical Ecology, Cambridge, v. 4, n. 3, p. 281-292, 1988.

LOCARNO, M.; FOCHI, C. G.; PAIVA, P. D. O. Influencia da adubação silicatada no teor de clorofila em folhas de roseira. Ciência e Agrotecnologia, Lavras, v. 35, n. 2, p. 287-290, 2011.

MA, F. J.; MIYAKEY, Y.; TAKAHASHI, E. Silicon as a beneficial element for crop plants. In: DATINOFF, L. E.; SYDER, G. H.; KORNDORFER, G. H. (Ed.). Silicon on agriculture. Amsterdam: Elsevier Science, 2001. p. 1739.

MEYERS, K. J.; WATKINS, C. B.; PRITTS, M. P.; LIU, R. H. Antioxidant and antiproliferative activities of strawberries. Journal of Agricultural and Food Chemistry, Washington, v. 51, n. 23, p. 6887-6892, 2003.
MINOLTA, C. Manual for chlorophyll meter SPAD502. Osaka: Minolta Radiometric Instruments Divisions, 1989. $22 \mathrm{p}$.

MITCHELL, F. G.; MITCHAM, E.; THOMPSON, J. E.; WELCH, N. Handling strawberries for fresch market. Oakland, CA: University of California, 1996. 14 p.

MIYAKE, Y.; TAKAHASHI, E. Effect of silicon on the growth and fruit production of strawberry plants in a solution culture. Soil Science and Plant Nutrition, Tokyo, v. 32, n. 2, p. 321-326, 1986.

MURILLO-AMADOR, B.; YAMADA, S.; YAMAGUSHI, T.; RUEDA-PUENTE, E.; ÁVILASERRANO, N.; GARCIA-HERNANDES, L.; LÓPEZ-AGUIAR, R. TROYODIEGUEZ, E.; NIETOGARIBAY, A. A. influence of calcium silicate on growth, physiological parameters and mineral nutrition in two legume species under salt stress. Journal of Agronomy and Crop Science, Berlin, v. 193, n. 6, p. 413-421, 2007.

NAMESNY, A. Posrecolección de hortalizas: III hortalizas de fruto. Barcelona: Ediciones Horticultura S. L., 1999. 302 p.

PEREIRA, H. S.; VITTI, G. C.; KORNDÖRFER, G. H. Comportamento de diferentes fontes de silício no solo e na cultura do tomateiro. Revista Brasileira de Ciência de Solo, Viçosa, v. 27, n. 1, p. 101-108, 2003.

PREZOTTI, L. C. Nutrição mineral do morangueiro. In: BALBINO, J. M. S. (Ed.). Tecnologias para produção, colheita e pós-colheita de morangueiro. 2. ed. Vitória: Incaper, 2006. p. 37-40.

PULZ, A. L.; CRUSCIOL, C. A. C.; LEMOS, L. B.; SORATTO, R. P. Influência de silicato e calcário na nutrição, produtividade e qualidade da batata sob deficiência hídrica. Revista Brasileira de Ciência do Solo, Viçosa, v. 32, n. 4, p. 1651-1659, 2008.

RAIJ, B. van; CANTARELLA, H.; QUAGGIO, J. A.; FURLANI, A. M. C. Recomendações de adubação e calagem para o Estado de São Paulo. 2. ed. Campinas: Instituto Agronômico de Campinas, 1997. 285 p. (Boletim técnico, 100).

RAVEN, J. A. The transport and function of silicon in plants. Biological Reviews of the Cambridge Philosophical Society, Cambridge, v. 58, n. 1, p. 179207, 1983.

REIS, T. H. P.; GUIMARÃES, P. T. G.; FIGUEIREDO, F. C.; POZZA, A. A. A.; NOGUEIRA, F. D.; RODRIGUES, C. R. O silício na nutrição e defesa de plantas. Belo Horizonte: EPAMIG, 2007. 119 p. (Boletim técnico, 82). 
SANTOS, G. R.; KORNDÖRFER, G. H.; REIS FILHO, J. C. D.; PELÚZIO, J. M. Adubação com silício: influência sobre as principais doenças e sobre a produtividade do arroz irrigado por inundação. Revista Ceres, Viçosa, v. 50, n. 1, p. 1-8, 2003.

SAVANT, N. K.; KORNDÖRFER, G. H.; SNYDER, G. H.; DATNOFF, L. E. Silicon nutrition and sugarcane production. A review Journal of Plant Nutrition, New York, v. 12, n. 12, p. 1853-1903, 1999.

SILVA, J. B. C.; GIORDANO, L. B. Tomate para processamento industrial. Brasília: Embrapa Comunicação para Transferência de Tecnologia, Embrapa Hortaliças, 2000. 168 p.

TAIZ, L.; ZEIGER, E. Fisiologia vegetal. 3. ed. Porto Alegre: Artmed Editora, 2004. 719 p.

THORNBER, J. P. Chlorophyll-proteins: light-harvesting and reaction center components of plants. Annual Review of Plant Physiology, New York, v. 26, n. 1, p. 127-158, 1975.
VIGNOLO, G. K.; ARAUJO, V. F.; KUNDE, R. J.; SILVEIRA, C. A. P.; ANTUNES, L. E. C. Produção de morangos a partir de fertilizantes alternativos em préplantio. Ciência Rural, Santa Maria, v. 41, n. 10, p. 1755 1761, 2011.

WANG, S. Y.; GALLETTA, G. J. Foliar application and potassium silicate induces metabolic changes in strawberry plants. Journal Plant Nutrition, London, v. 21, n. 1, p. 157-167, 1998.

WHATLEY, J. M.; WHATLEY, F. R. A luz e a vida das plantas. São Paulo: EPU-EDUSP, 1982. 101 p.

ZHANG, Y.; VAREED, S. K.; NAIR, M. G. Human tumor cell growth inhibition by nontoxic anthocyanidins, the pigments in fruits and vegetables. Life Sciences, Sweden, v. 76, n. 13, p. 1465-1472, 2005. 